\title{
MASS MOVEMENTS DETECTION FROM UAV IMAGES ANALYSIS
}

\author{
V. Morocho ${ }^{1 *}$, D. A. España ${ }^{2}$, A. C. Serrano ${ }^{2}$, R. Achig ${ }^{1}$, J. Crompvoets ${ }^{3}$ \\ ${ }^{1}$ Computer Science Department, University of Cuenca, Cuenca, Ecuador - (villie.morocho, rosario.achig)@ucuenca.edu.ec \\ ${ }^{2}$ Engineering Faculty, University of Cuenca, Cuenca, Ecuador - (andres.espana, carolina.serranot)@ucuenca.edu.ec \\ ${ }^{3}$ Public Governance Institute, KU LEUVEN, Leuven, Belgium - joep.crompvoets@kuleuven.be
}

KEY WORDS: Landslide, mass movements, detection of mass movements.

\begin{abstract}
:
Biophysical conditions, the lack of governance and the weak applications of planning and territorial planning policies are aggravating factors of affections caused by natural disasters in Latin America. In Ecuador, landslides have caused not only material but also human losses, which shows the lack of immediate actions to avoid human settlements in risk areas or more controlled evacuations protocols, in case of early detection of risk areas due to this type of events. This article is part of an applied research project for the City of Cuenca allowing to take advantage of the information provided by citizens with a PPGIS. Furthermore, remote sensor images are analyzed, in order to identify in a semi-automated way, risk areas due to mass movements problems. Two approaches for semi-automated detecting areas where mass movements happen have been explored, i) Temporal images obtained by a LiDAR; and ii) Temporary images obtained by flights of an unmanned aerial vehicle, UAV. This paper present the procedure followed by comparison of image outcomes. The resulting analysis clearly presents the applicability of the two techniques thus allowing the determination of maps and early detection of landslides.
\end{abstract}

\section{INTRODUCTION}

Biophysical conditions, lack of governance, weak planning and territorial policies, among others, are aggravating causes for suitable managing events caused by natural disasters in Latin America. In the case of Ecuador, landslides have caused not only material but also human losses, which shows that land management still owes society guarantees for the correct use and occupation of the territory; in this scenario, this research focuses on studying aspects related to landslides evolution.

A landslide is the movement downhill of a soil or rock mass that occurs predominantly on well-defined breaking surfaces or on relatively narrow areas of intense shear (Cruden \& Varnes, 1996). Landslides are highly destructive geological processes that affect humans and causing thousands of deaths and property damage, amounting to tens of billions of dollars each year (Brabb \& Harrod, 1989).

Landslide monitoring can be performed by terrestrial geodesic techniques such as total stations, leveling and theodolites; satellite techniques with GPS; Geotechnical methods such as the extensometer; terrestrial photogrammetry (Travelletti et al., 2012), Unmanned Aerial Vehicles (UAV) (Dewitte et al., 2008); Satellite images (Behling \& Roessner, 2017) among many other alternatives. The detection of landslides over the big areas is a major problem and such study demands economic and human resources and long measurement periods, taking usually weeks or months. Additionally, the changing climatic conditions in recent times produce morphologic variations, for example, due to accelerated precipitation. In Ecuador, there are severe problems caused by heavy rains resulting into landslides. Therefore, it is necessary to look for solutions to improve the process of detection of risk areas of mass movements.

A project, entitled as "Spatial Data Infrastructure geo-processing for landslide vulnerability assessment and territorial planning", was developed at the University of Cuenca. As a first step involved citizens through PPGIS links in order to speeding up the process of capturing crucial information on landslides. The second step deals with, the necessary measurement by nottraditional technique such as UAV. This paper focuses on the use of UAVs for identifying landslide zones.

Two approaches have been explored, i) the use of LiDAR with long processing time for obtaining temporal images for a small area (section 2.1); ii) and UAVs with short processing time, for obtaining the temporary images (section 2.2). The paper includes a comparison between these approaches, conclusions and future works.

\section{METHODS}

\subsection{LiDAR point cloud generation.}

The characteristics of LiDAR and UAV information processing equipment are as follow: Intel (R) Xeon (R), CPU ES-2640 v2 @ $2.00 \mathrm{GHz} ., 12$ threads, 16.0 GB of RAM, Windows 10 pro, 64 bits, graphics card NVIDIA GPU, Quadro K2000 (Driver: 23.21.13.8816); FARO 3D X130 terrestrial laser scanner (Light Detection and Ranging) with a range of $130 \mathrm{~m}$. and an accuracy of $\pm 2 \mathrm{~mm}$. Laser scanner deliver convenient results over instable areas, and it is ideal for studding landslides (Revuelto et al., 2013).

In order to generate the point cloud, 23 survey were undertaken of which, 15 on December 6, 2017 (Upper zone) and 8 on December 7, 2017 (Lower zone).

The study area was determined with the help of PPGIS. Figure 1 shows the study area with a size 10 hectares. This zone is located in the Ecuadorian highlands ( $2^{\circ} 55$ ' 65 "S, 79 $09^{\circ}$ ' 05" W, elevation around $2530 \mathrm{~m}$ ) with cloudiness conditions and winds that oscillate around $10 \mathrm{~m} / \mathrm{s}$.

\footnotetext{
* Corresponding author
} 


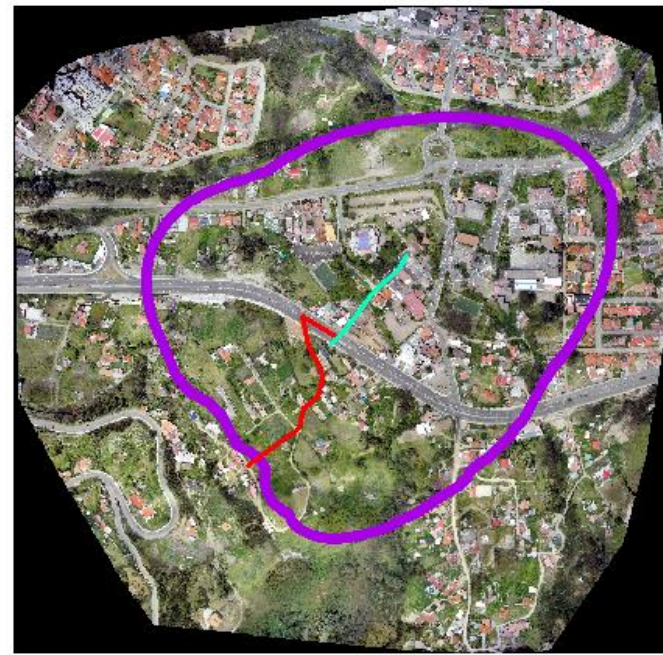

- Lower zone — Upper zone Study zone

Figure 1. Study area, Cuenca - Ecuador. Distribution of scan zones

2.1.1 LiDAR processing. FARO SCENE (C) was the processing software for the point cloud. Figure 2 illustrates a common processing screen, typical of the LiDAR technology, in which each of survey links by means of target correspondences associated with small spheres of $0.0698 \mathrm{~cm}$ radius and large spheres of $0.12335 \mathrm{~cm}$ radius. In addition, for the case of spheres with large errors, reference planes were used. Each pair of continuous scans had a minimum of 3 correspondence points (Barbarella \& Fiani, 2013).

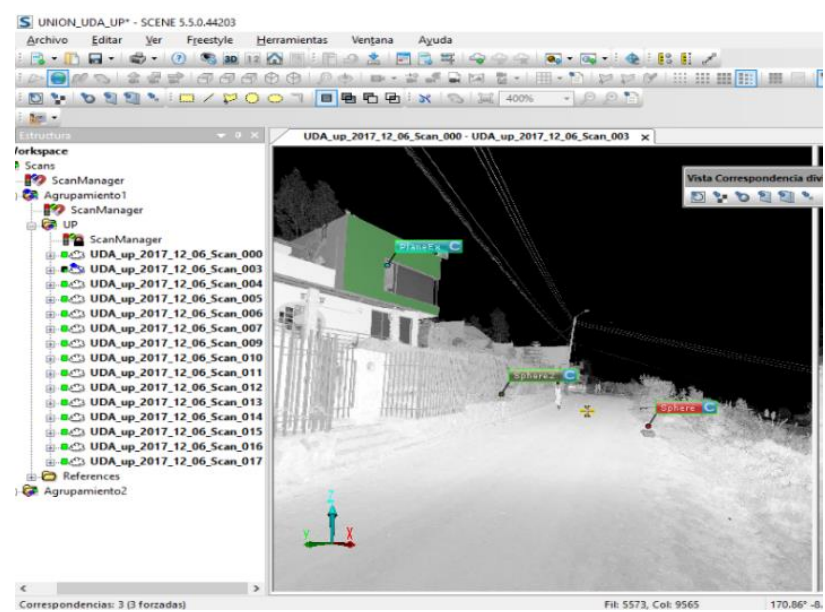

Figure 2. Union of point clouds of LiDAR using the FARO SCENE Software.

Due to the high number of points obtained from LiDAR, it was necessary to set up a simplification process by means of Octree function from Cloud Compare $(\subset$ allowing to reduced the quality of point clouds to a quarter of its size.

Table 1 presents the average processing times of the executed processes.
Table 1. Average processing times using LiDAR software.

\begin{tabular}{|c|c|}
\hline Process & Average time \\
\hline Individual import of point cloud. & $2 \mathrm{~min}$ \\
\hline Individual load of point cloud. & $5 \mathrm{~min}$ \\
\hline Individual coloring of scans & $5 \mathrm{~min}$ \\
\hline $\begin{array}{c}\text { Forcing of correspondences for } \\
\text { each pair of point cloud by the } \\
\text { user }\end{array}$ & $10 \mathrm{~min}$ \\
\hline \begin{tabular}{c} 
Exporting joined point clouds. \\
\hline Saved of the project
\end{tabular} \\
\hline $\begin{array}{c}\text { Individual simplification of point } \\
\text { cloud (upper and lower) }\end{array}$ \\
\hline $\begin{array}{c}\text { Point clouds alignment } \\
\text { (upper and lower) }\end{array}$ & $35 \mathrm{~min}$ \\
\hline
\end{tabular}

2.1.2 Errors obtained in LiDAR processing. The errors obtained in the point clouds alignment (of the fifteen surveys on December 6, located in the upper area) had a maximum error of $6.7 \mathrm{~mm}$ between scans, when joining a plane 4 in the 005 and 003 scans. The average error was $0.5 \mathrm{~mm}$ with a deviation of 1 $\mathrm{mm}$.

The errors obtained in the point clouds alignment (of the eight surveys on December 7, located in the lower area) had a maximum error of $7.4 \mathrm{~mm}$ between scans, when joining a sphere 3 in the 030 and 035 scans. The average error was $1.2 \mathrm{~mm}$ with a deviation of $1.7 \mathrm{~mm}$.

\subsubsection{Point clouds alignment (Upper and lower zones).}

From the generation process described in 2.2 , two different point clouds were obtained with an intermediate zone in between, which help to join both point clouds. The point clouds were joined using CloudCompare with 5 uniformly distributed common points.

The 5 points were placed in the following way: One on a pole (A0 and R0), one on a sign (A1 and R1), two on the railing of the Cuenca Azogues highway (A2 and R2, A3 and R3) and one on a fixed object (A4 and R4). The errors obtained in this alignment had a maximum error of $5 \mathrm{~mm}$ in points $\mathrm{A} 4$ and $\mathrm{R} 4$, as shown in Figure 3. The point cloud that resulted from this alignment was used for the comparison study (LiDAR - UAV).

\subsection{Generation of point clouds using UAV}

The equipment for processing the UAV images was the eBee ${ }^{\circledR}$ RTK - SenseFly® with GNSS antenna and RTK capability, allowing real-time corrections. This equipment allows obtaining orthomosaics, point clouds and digital elevation model (DEM) with an accuracy of $3 \mathrm{~cm}$, in good weather conditions, or up to 8 $\mathrm{cm}$ in low light and wind conditions (Roze, Zufferey, Beyeler, \& McClellan, 2014).

UAV images processing steps are: images selection for the program, camera calibrating, finding homologous points, and identification points over terrain. For this case, the UAV already made geo-referencing and corrections in real time, triangulations to better adjust the image, reconstructing the images using points, generating point cloud, orthophotos and DEM (Núñez Calleja, 2016). 


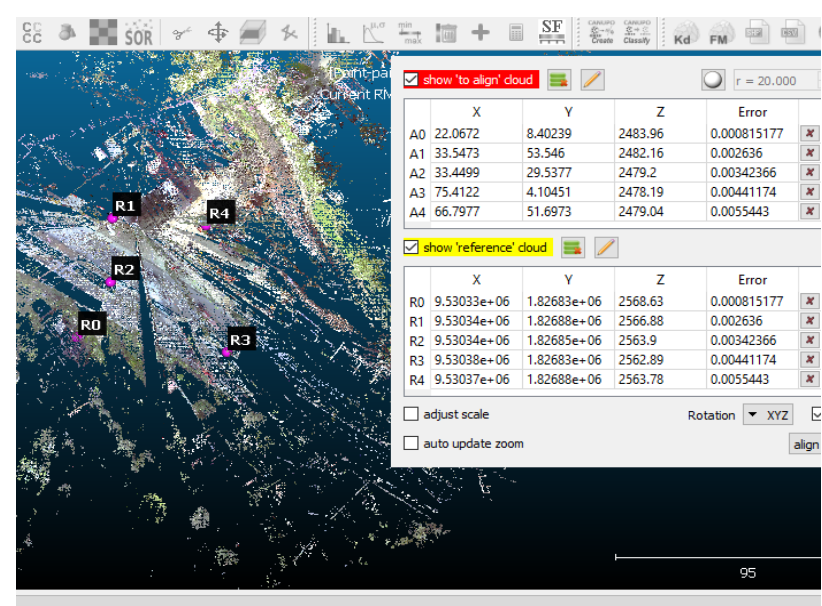

Figure 3 Error values in the alignment of the upper and lower zones for the study area

2.2.1 Point cloud from February 2, 2018. The processing of the point cloud was executed with Pix4D®. Table 2 shows the steps taken, with the corresponding information.

Table 2. Processing of UAV images, from February 2, 2018.

\begin{tabular}{|c|c|}
\hline Process & Description \\
\hline $\begin{array}{c}\text { Resolution (Average Ground } \\
\text { Sampling Distance GSD) }\end{array}$ & $4.5 \mathrm{~cm}$ \\
\hline Images used & $396 \mathrm{de} 397$ \\
\hline Re-projection average error & $0.197 \mathrm{~m}$ \\
\hline $\begin{array}{c}\text { Average number of key points } \\
\text { per image (2D) }\end{array}$ & 48120 \\
\hline $\begin{array}{c}\text { Average number of key points } \\
\text { matched per image (2D) }\end{array}$ & 10212 \\
\hline
\end{tabular}

The distribution of the $2 \mathrm{D}$ correspondences is illustrated in Figure 4. The errors in the processing of UAV images are presented in Table 3.

Table 3. Geolocation errors, point cloud from Feb 20, 18.

\begin{tabular}{|c|c|c|c|}
\hline & $\begin{array}{c}\text { Geolocation } \\
\text { errror X(\%) }\end{array}$ & $\begin{array}{c}\text { Geolocation } \\
\text { errror Y(\%) }\end{array}$ & $\begin{array}{c}\text { Geolocation } \\
\text { errror Z(\%) }\end{array}$ \\
\hline Mean [m] & 0.022192 & -0.017020 & -0.058113 \\
\hline Sigma [m] & 0.573481 & 0.516043 & 0.731767 \\
\hline RMS Error (m) & 0.573910 & 0.516324 & 0.734071 \\
\hline
\end{tabular}

Once the points have been georeferenced and oriented, point clouds were generated. Additional processes were described in Table 4, where processing times are also shown. Therefore, it is possible to determine the speed to achieve a complete processing in the implementation of this methodology, as a possible solution of semi-automated generation of vulnerability maps.

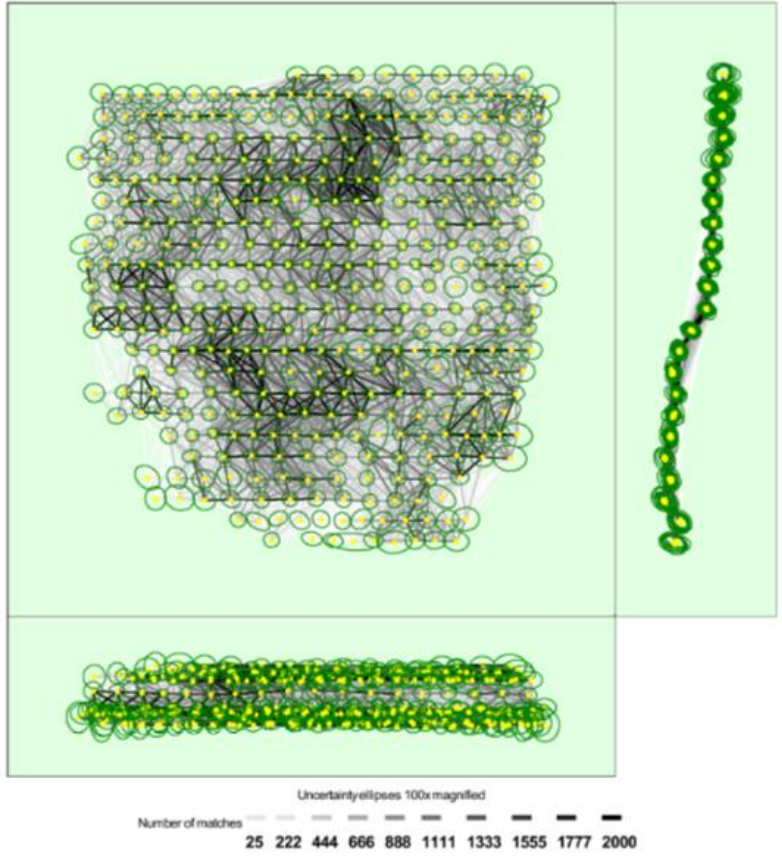

Figure 4. Approved points and camera uncertainty of the point cloud (Feb 2, 18)

Table 4. Processing times (02-feb-18)

\begin{tabular}{|c|c|}
\hline Process & Average time \\
\hline Initial processing & $1 \mathrm{~h}: 5 \mathrm{~min}: 28 \mathrm{~s}$ \\
\hline Point cloud densification & $2 \mathrm{~h}: 28: 40 \mathrm{~s}$ \\
\hline 3D mesh generation & $41 \mathrm{~min}: 38 \mathrm{~s}$ \\
\hline Generation of DMS & $5 \mathrm{~h}: 29 \mathrm{~min}: 46 \mathrm{~s}$ \\
\hline Generation of orthomosaics & $1 \mathrm{~h}: 42 \mathrm{~min}: 43 \mathrm{~s}$ \\
\hline
\end{tabular}

2.2.2 Point cloud from June 20, 2018. Normally, the rainy season in the city of Cuenca is from January to June. For this study, another flight was carried out in the month of June, to make a comparison of images and determine the possibility of using them to detect areas that have suffered mass movements.

Table 5. Processing of UAV images (Jun 20, 18)

\begin{tabular}{|c|c|}
\hline Process & Description \\
\hline $\begin{array}{c}\text { Resolución (Average Ground } \\
\text { Sampling Distance GSD) }\end{array}$ & $4.55 \mathrm{~cm}$ \\
\hline Images used & $370 \mathrm{de} 376$ \\
\hline Re-projection average error & $0.242 \mathrm{~m}$ \\
\hline $\begin{array}{c}\text { Average number of key points } \\
\text { per image (2D) }\end{array}$ & 62798 \\
\hline $\begin{array}{c}\text { Average number of key points } \\
\text { matched per image (2D) }\end{array}$ & 13608 \\
\hline
\end{tabular}

Figure 5 depicts the distribution of the $2 \mathrm{D}$ correspondences and Table 6 shows the errors in the processing of the UAV images. 


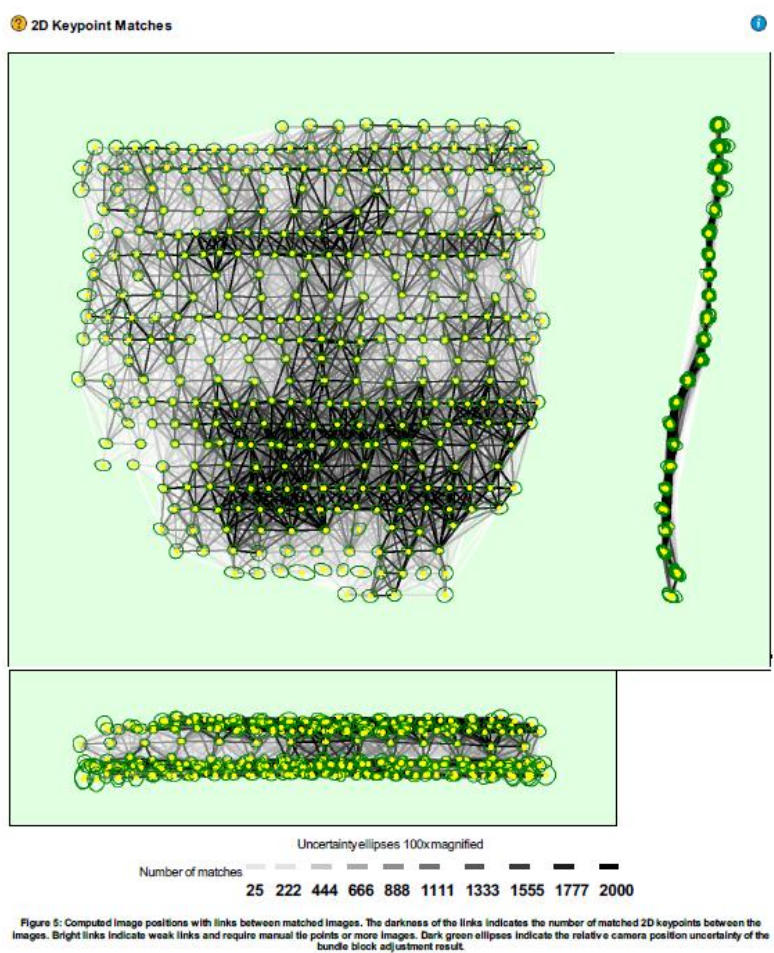

Figure 5. Approved points and camera uncertainty of the point cloud (Jun 20, 18)

Table 6. Geolocation errors, point cloud from Jun 20,18

\begin{tabular}{|c|c|c|c|}
\hline & $\begin{array}{c}\text { Geolocation } \\
\text { error X(\%) }\end{array}$ & $\begin{array}{c}\text { Geolocation } \\
\text { error Y }(\%)\end{array}$ & $\begin{array}{c}\text { Geolocation } \\
\text { error Z(\%) }\end{array}$ \\
\hline Mean [m] & 0.007755 & -0.004583 & 0.004504 \\
\hline Sigma [m] & 0.453180 & 0.360344 & 0.594581 \\
\hline RMS Error (m) & 0.453246 & 0.360374 & 0.594598 \\
\hline
\end{tabular}

The processing time of this point cloud is included in Table 7.

Table 7. Processing times, UAV images from Jun 20, 18

\begin{tabular}{|c|c|}
\hline Process & Average time \\
\hline Initial processing & $1 \mathrm{~h}: 50 \mathrm{~min}: 8 \mathrm{~s}$ \\
\hline Point cloud densification & 14h:50min:00s \\
\hline 3D mesh generation & $1 \mathrm{~h}: 33 \mathrm{~min}: 3 \mathrm{~s}$ \\
\hline
\end{tabular}

\section{POINT CLOUDS REFERENCING}

Once processed the clouds of time points, both LiDAR and UAV, the work consists of looking for differences existing between the profiles chosen within the study area. To achieve this, the following two steps are proposed: a) reference the two images based on reference points; b) compare two profiles (cuts) of the point cloud.

The point clouds alignment, taken in the dates to be compared, was carried out, so that all points were georeferenced according to the same reference, with an acceptable error. The CloudCompare tool was used to align two clouds of points with equivalent points; for this, at least three fixed points, equivalent in both clouds, had to be selected. ("CloudCompare - Open Source project", s.f.)
It is necessary to mention that the study area has been suffering several mass movements since the construction of a highway that crosses through it. Figure 6 shows the highway that divides the study area into two parts. The northern zone (top of the photo) at an altitude of $2520 \mathrm{~m}( \pm 10 \mathrm{~m})$ above sea level, and the southern zone (bottom of the photo) at an altitude of $2600 \mathrm{~m}( \pm 25 \mathrm{~m})$.
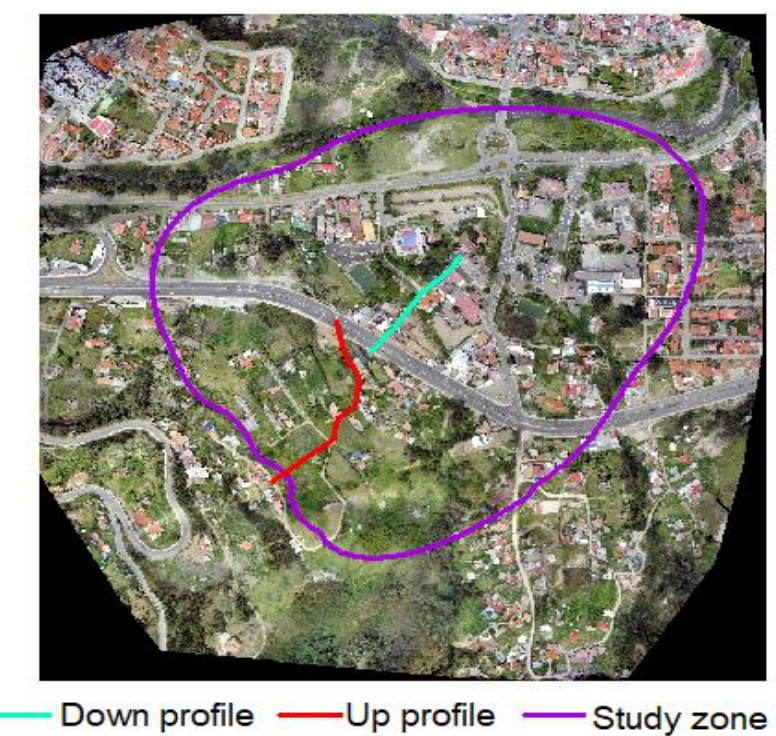

Figure 6 Study zone. Location of profiles UP, DOWN.

\subsection{Geo-referencing LiDAR (Dec 06, 17)-UAV (Feb 02, 18)}

To perform the referencing, five points located in the upper corners of different premises were taken. Four of them located in the upper part of the escarpment, an area in which there are no movements, and the other point located in the corner of a building, where mass movement produces displacements in the field. Figure 7 illustrate the location map of the selected points.

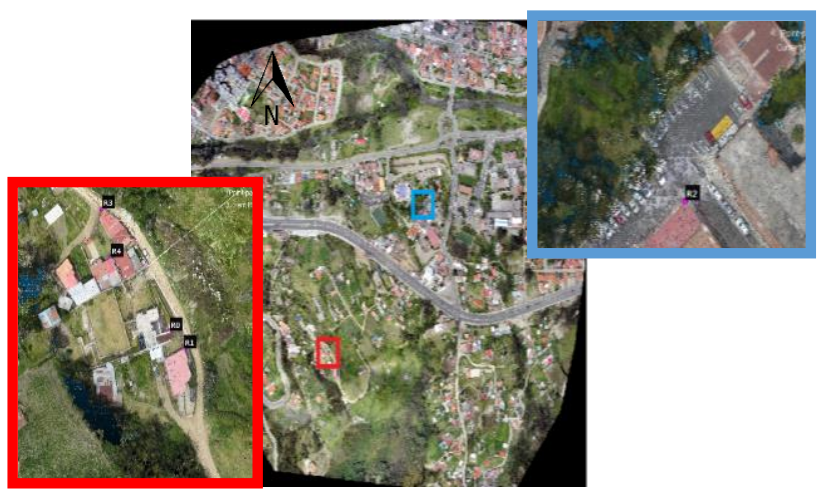

Figure 7. Map of the selected geo-referencing points.

The alignment of these points produced a maximum error of 3.5 $\mathrm{cm}$ at the point $\mathrm{A} 3-\mathrm{R} 3$, located in the southwest area, and a minimum of $5 \mathrm{~mm}$ in the central area. Considering itself acceptable since the accuracy of the UAV is $3 \mathrm{~cm}$. Figure 8 depicts the geo-referencing errors associated with the Lidar-UAV images. 


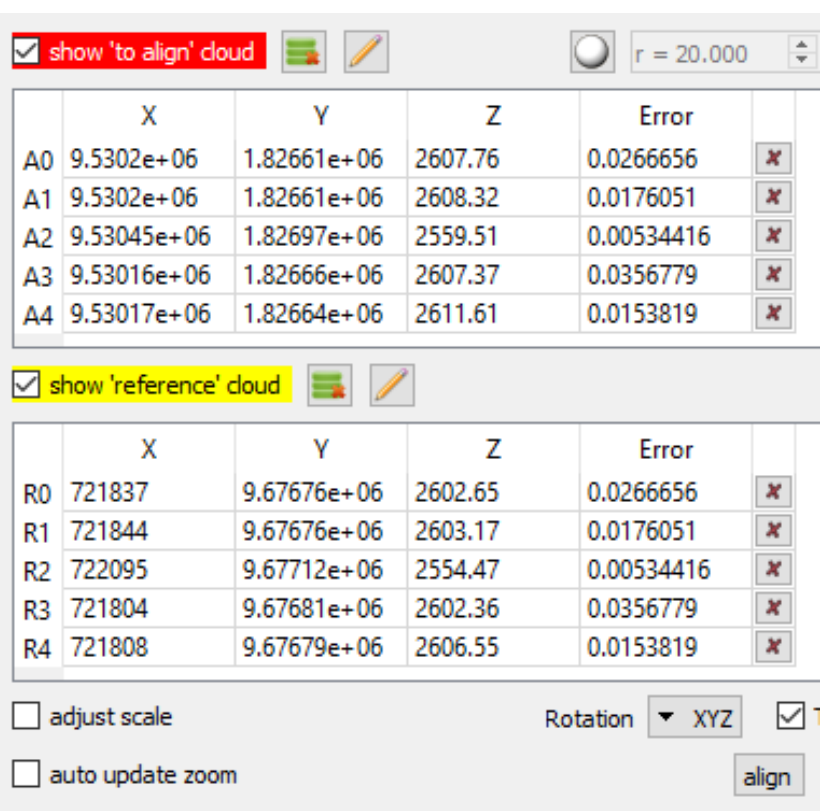

Figure 8. Geo-referencing errors, Lidar - UAV.

\subsection{Geo-referencing UAV Feb 02, 18 - UAV Jun 20, 18.}

The same process was performed, with the point clouds of the temporary images of the UAV, using five points evenly distributed, as illustrated in Figure 9.

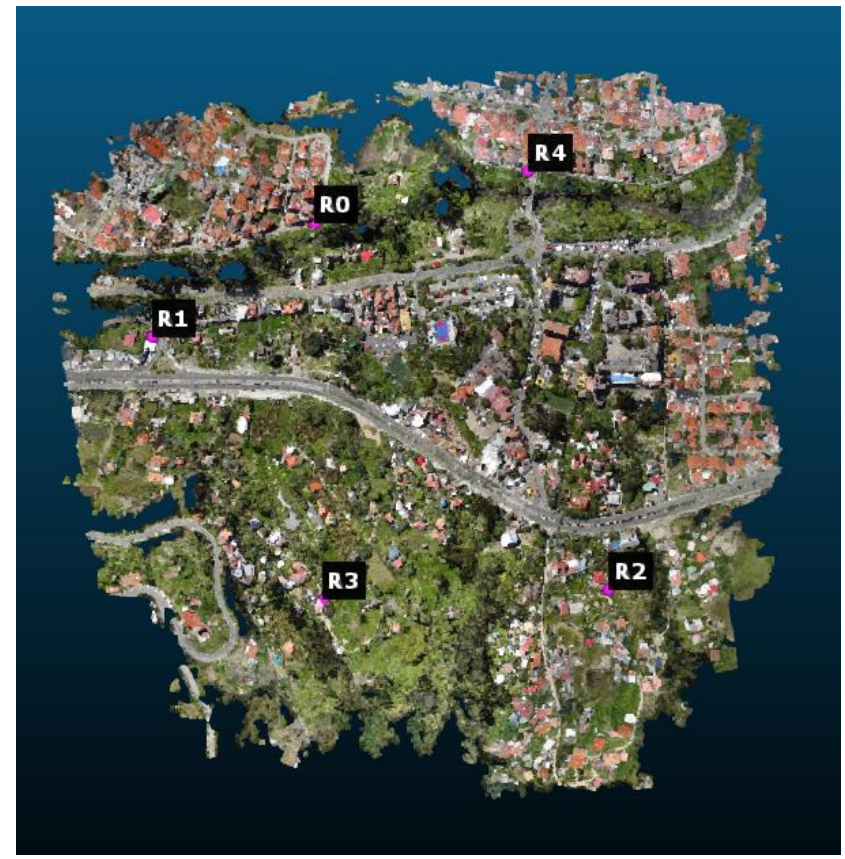

Figure 9. Reference points locations UAV - UAV.

In this alignment, a maximum error of $3.7 \mathrm{~cm}$ was obtained in the A1 - R1 point, close to the highway, towards the northwest of the zone, and a minimum error of $5.2 \mathrm{~mm}$ in $\mathrm{A} 2-\mathrm{R} 2$, to the southeast of the studied area. Geo-referencing errors of the UAV-UAV images are summarized in Figure 10.

Table 8 summarizes the processing times for the point clouds before comparison, using the equipment described above.

\begin{tabular}{|c|c|c|c|c|c|}
\hline \multicolumn{3}{|c|}{$\square$ show 'to align' cloud $\equiv$} & 0 & \multicolumn{2}{|c|}{$r=20.000 \quad \forall \quad l$} \\
\hline & $\mathrm{x}$ & $\mathrm{Y}$ & Z & Error & \\
\hline All & 721835 & $9.67733 \mathrm{e} . .$. & 2533.19 & 0.0235947 & $x$ \\
\hline$\Delta 1$ & 721587 & $9.67716 \mathrm{e} \ldots$ & 2564 & 0377754 & $x$ \\
\hline A) & 722283 & $9.67677 \mathrm{e} \ldots$ & 2591.33 & $0.005246 \ldots$ & $x$ \\
\hline$A 2$ & 721848 & $9.67676 \mathrm{e} \ldots$ & 2596.01 & 2586 & $x$ \\
\hline \multicolumn{6}{|c|}{$\square$ show 'reference' cloud } \\
\hline & $x$ & Y & Z & Error & \\
\hline R1 & 721587 & $9.67716 \mathrm{e} \ldots$ & 2563.52 & 0.0377754 & $x$ \\
\hline k) & 722283 & $9.67677 \mathrm{e} \ldots$ & 2591.46 & $0.005246 \ldots$ & $x$ \\
\hline $\mathrm{K} 2$ & 721848 & $9.67676 \mathrm{e} .$. & 2595.62 & 0.0272586 & $x$ \\
\hline R4 & 722161 & $9.67741 \mathrm{e} \ldots$ & 2529.15 & 0.0351505 & $x$ \\
\hline \multicolumn{3}{|c|}{$\square$ adjust scale } & Rotation & $\checkmark X Y Z \square$ & $T x$ \\
\hline \multicolumn{3}{|c|}{$\square$ auto update zoom } & & align & $r \epsilon$ \\
\hline
\end{tabular}

Figure 10. Geo-referencing errors, UAV - UAV.

Table 8. Processing times for geo-referencing of point clouds

\begin{tabular}{|c|c|}
\hline Process & Average time \\
\hline $\begin{array}{c}\text { Location of equivalent points in } \\
\text { each cloud }\end{array}$ & 1 hour \\
\hline $\begin{array}{c}\text { Individual alignment of point } \\
\text { clouds }\end{array}$ & $15 \mathrm{~min}$ \\
\hline
\end{tabular}

Once completed the point clouds alignments, it was possible to extract the profiles proposed for the study and thus applicable for the respective comparison.

\section{DETECTION OF MASS MOVEMENTS BASED ON THE EXTRACTED POINT CLOUDS}

The segmentation method for scanning profile was used for comparing profiles, consisting segmenting the point cloud following lines or profile. This technique consists of freely drawing a profile, looking to cross perpendicularly the points sent by the citizens through PPGIS. The tracing of this line can be done where it is most convenient, in this case, it was where the LiDAR scanner was fixed for scanning (Gonzalez, Woods, \& Eddins, 2004).

Then, the profile representation was created using AutoCAD ${ }^{\circledR}$ Civil 3D 2018 using the profiles extracted from the point clouds. This allows obtaining transversal profiles with the respective relevant information. («CARTOGRAPHY AND TOPOGRAPHY PRACTICES», s.f.).

\subsection{Procedure with profiles}

Figure 6 presents two profiles for each point cloud obtained in the section, one of the upper zone of the highway (Up profile) and another one in the lower zone of the highway (Down profile). The cut of the point cloud is extracted in a ".las" format, which has to be transformed to a ".rcp" format before being used in AutoCAD® Civil 3D. On the Up profile is the upper part of the escarpment, which corresponds to a pasture and several unpaved roads leading to the highway. According to the information provided by the citizen through PPGIS, in this area there is a visible mass movement. 


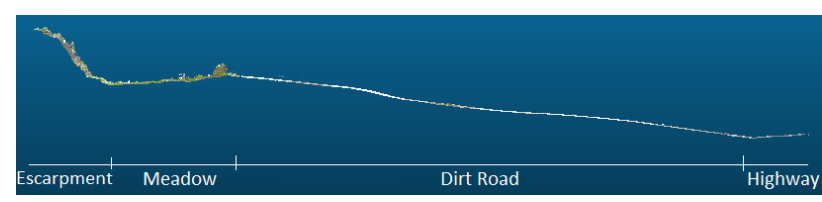

Figure 11. Up profile distribution.

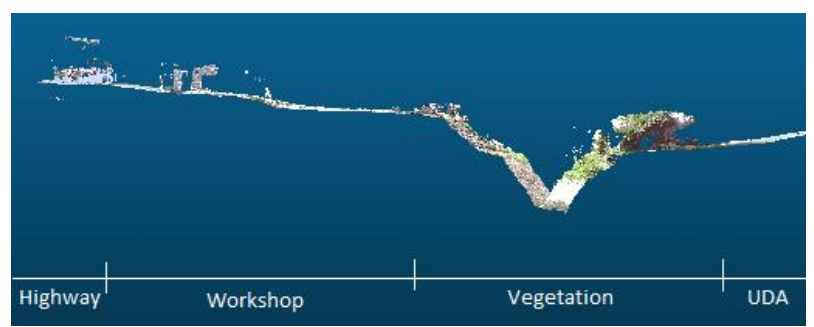

Figure 12. Down profile distribution.

Once the Up and Down profiles of each point cloud were obtained, 6 in total, they were compared using AutoCAD Civil 3D 2018. Figure 11 and Figure 12 correspond to the Up and Down profile distributions, respectively. The methodology consists of: 1) loading the point clouds; 2) creating cloud surfaces; 3 ) drawing a line inside the clouds; 4) creating a quick profile of that line and customizing the information of the obtained transversal profile. Figure 13 depicts the creation of the Up transversal profile for Jun 20, 18 point cloud.

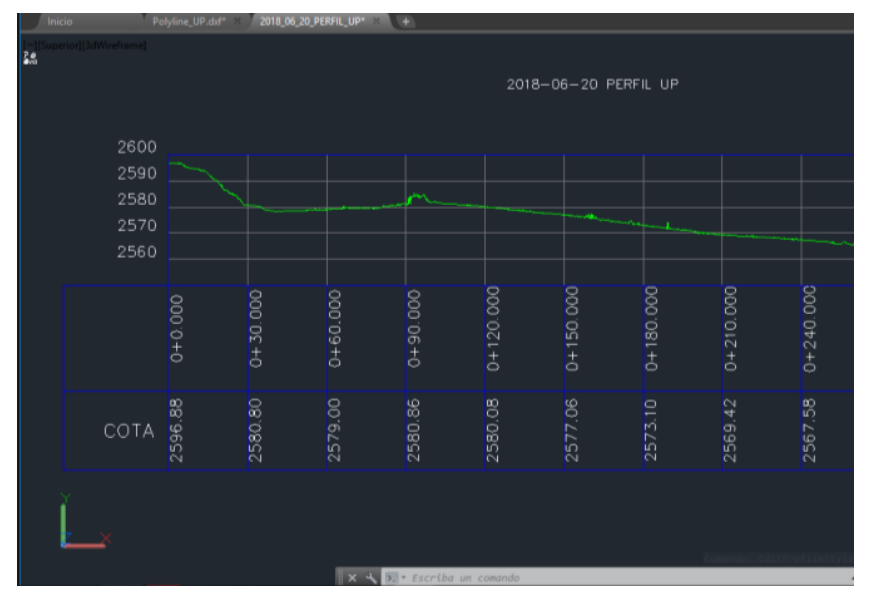

Figure 13. Up transversal profile creation, Jun 20, 18.

The average time for profile processing is around 30 minutes per profile. In this case study, they were processed 4 times to cover all profiles.

\section{RESULTS}

For the comparison of profiles, the dimensions of each of the point clouds and their differences were analyzed. The Up profiles were divided into $10 \mathrm{~m}$ intervals on their abscissa, and $10 \mathrm{~m}$ intervals on their dimensions. The Down profiles were divided into intervals of $15 \mathrm{~m}$ on their abscissa and intervals of $5 \mathrm{~m}$ on their heights.

\subsection{Profiles comparison, LiDAR Dec 07, 17 - UAV Feb 02,} 18.

Figure 14 presents the detailed results, however, the most relevant differences are in the area of the escarpment $(0+$ $010,000-0+030,000)$, where it is observed subsidence of 33 $\mathrm{cm}$ and $18 \mathrm{~cm}$. It can be deduced that it is the result of collapse due to rain and other factors; finally, a $3.9 \mathrm{~cm}$ rise is observed in the terminal part of the escarpment, which may indicate accumulation of material by its deflection. Between this section and the next there is a vegetation zone for which it is not possible to determine the accuracy of the calculations.

5.1.1 Up profile. On the dirt road $(0+110,000-0+$ 210.000), there is a ground uplift that ranges from $6 \mathrm{~mm}$ to $9 \mathrm{~cm}$. This indicates a landmass advance, which would justify the existence of slight structural damage in the surrounding homes, which were reported by the PPGIS. The values passed $10 \mathrm{~cm}$ may be due to noise or small topographic changes.

In the final part of the profile, dirt road to the highway $(0+$ $220,000-0+290,000)$, there is a slight uplift of earth with only subsidence, around $10 \mathrm{~cm}$, which represents an advance of the land mass or they may be the result of the wave movement of the slip.

5.1.2 Down profile. Figure 15 shows in more detail the analysis where it is appreciated, that in the profile where a car workshop goes through $(0+015.000-0+060.000)$ there are uplifts and subsidence ranging from $9 \mathrm{~cm}$ to $69 \mathrm{~cm}$. In this area there is movement of heavy machinery that can cause more abrupt changes between the aerial shots and the topography of the terrain.

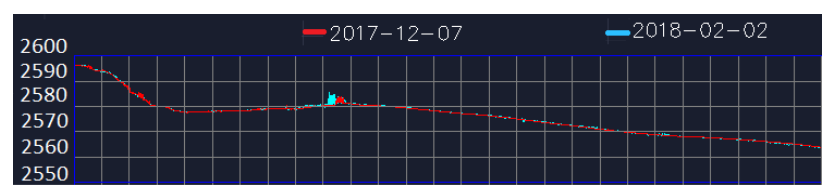

Figure 14. Comparison of profile Up

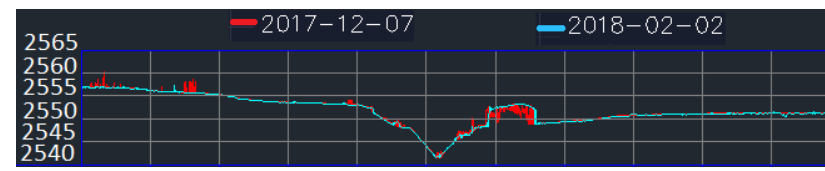

Figure 15. Comparison of profile Down

\subsection{Profiles comparison UAV Feb 02, 18 - UAV Jun 20, 18.}

5.2.1 Up profile. In the abscissa $0+000.000$, it can be observed that the difference between profiles is $35.2 \mathrm{~cm}$. In this zone, the error does not approach 0 and the maximum joint error is $3.77 \mathrm{~cm}$, due to errors of re-projection of both point clouds, which are $0.242 \mathrm{~m}$ and $0.197 \mathrm{~m}$, respectively, or by the distribution of homologous points in each cloud.

Although there are vegetation zones in the profile, which do not facilitate the work, the most relevant data are in the areas of dirt roads.

On the dirt road $0+110,000-0+210,000$, a lift from $70 \mathrm{~cm}$ to $50 \mathrm{~cm}$ is observed, which could also indicate an advance of the deflection, given that the uplift is maintained in a proportion similar to the previous profile.

In the continuation of the dirt road to the start of the highway ( 0 $+220,000-0+290,000)$ the same changes in the terrain can be observed, corresponding to uplifts between $50 \mathrm{~cm}$ and $70 \mathrm{~cm}$.

5.2.2 Down profile. In the parking of heavy machinery $(0+$ $015,000-0+060,000)$, it can be observed uplifts that range from $47 \mathrm{~cm}$ to $97 \mathrm{~cm}$, possibly due to the work done with heavy vehicles in that area. 


\section{CONCLUSIONS AND FUTURE WORK}

The anomalous terrain displacement values obtained when comparing the multi-temporal profiles of the University of Azuay landslide can be due to changes in vegetation height or anthropic activity such as earth movements, change vehicles and machinery position in the workshop area, remodeling the university parking, slope stabilization works in the ravine next to the university.

However, the anomalous values of terrain displacement obtained outside the landslide and in zones without vegetation or anthropic actions, show that the techniques of active remote sensing (terrestrial LiDAR) and passive photogrammetry drone at low altitude (UAV) used for this study, despite their accuracy, have not been sufficient to achieve the proposed objective in a reliable manner. The use of this modern technology (LiDAR and UAV) cannot replace the traditional geodetic surveying techniques in situ such as differential GPS and total station, as well as the indispensable use of control points. Modern remote sensing techniques to identify mass movements need to be complemented with traditional topography to ensure correct alignment of point clouds and surface models obtained with LiDAR and UAV, as well as to validate the measurements of the point clouds and multi-temporal surface models.

Despite this, the fact of being able to determine landslide zones by having large variations of measurements (higher values than the UAV preset of $3.5 \mathrm{~cm}$., added to the error introduced by processing, i.e. over of $7 \mathrm{~cm}$ ), had shown that these areas need increase of precision and thus it is required a total survey with precision equipment. Therefore, financial resources could be saved and improved the speed of response for generation of vulnerability maps by landslides.

\section{ACKNOWLEDGEMENTS}

The authors wish to thank the Research Directorate of the University of Cuenca for the research funds granted to the project "IDE Geoprocessing as support for vulnerability analysis and territorial planning". Also, thanks to Professor Enrique Acosta.

\section{REFERENCES}

Barbarella, M., \& Fiani, M. (2013). Monitoring of large landslides by Terrestrial Laser Scanning techniques: field data collection and processing. European Journal of remote sensing, 46(1), 126-151.

Behling, R., \& Roessner, S. (2017). Spatiotemporal landslide mapper for large areas using optical satellite time series data. En Workshop on World Landslide Forum (pp. 143-152).

Brabb, E. E., \& Harrod, B. L. (1989). Landslides: extent and economic significance. Proceedings of the 28th International Geological Congress: Symposium on Landslides.

Cruden, D., \& Varnes, D. (1996). Landslide types and processes. Transportation Research Board, Special Report, 247, 36-75.

Dewitte, O., Jasselette, J. C., Cornet, Y., Van Den Eeckhaut, M., Collignon, A., Poesen, J., \& Demoulin, A. (2008). Tracking landslide displacements by multi-temporal DTMs: A combined aerial stereophotogrammetric and LIDAR approach in western Belgium. Engineering Geology, 99(1-2), 11-22. https://doi.org/10.1016/j.enggeo.2008.02.006

Gonzalez, R. C., Woods, R. E., \& Eddins, S. L. (2004). Digital image processing using MATLAB. (Vol. 624). Pearson-PrenticeHall Upper Saddle River.

Núñez Calleja, P. (2016). Comparativa de software para la realización de ortofotos a partir de imágenes obtenidas por drones.

Revuelto, J., López-Moreno, J. I., Azorín-Molina, C., Arguedas, G., Vicente Serrano, S. M., \& Serreta Oliván, A. (2013). Utilización de técnicas de láser escáner terrestre en la monitorización de procesos geomorfológicos dinámicos: el manto de nieve y heleros en áreas de montaña.

Roze, A., Zufferey, J. C., Beyeler, A., \& McClellan, A. (2014). eBee RTK accuracy assessment. White Paper Sense Fly.

Travelletti, J., Delacourt, C., Allemand, P., Malet, J. P., Schmittbuhl, J., Toussaint, R., \& Bastard, M. (2012). Correlation of multi-temporal ground-based optical images for landslide monitoring: Application, potential and limitations. ISPRS Journal of Photogrammetry and Remote Sensing, 70, 39-55. https://doi.org/10.1016/j.isprsjprs.2012.03.007 